\title{
Usefulness of a general anesthesia protocol and work organization in mass castration and sterilization programs for dogs and cats
}

\author{
BEATA DEGÓRSKA, SONIA SKWAREK*, MAGDALENA BRALEWSKA*, PAWEŁ PIECHOTA*, \\ KAROLINA MAGIERA*, MIKOŁAJ KOŁUCKI*, MAREK GALANTY, MALWINA KOWALSKA*
}

\author{
Department of Small Animal Disease with Clinic, Faculty of Veterinary Medicine, \\ Warsaw University of Life Sciences - SGGW, Nowoursynowska 159c, 02-776 Warsaw, Poland \\ *Students of the Veterinary Medicine Club
}

Degórska B., Skwarek S., Bralewska M., Piechota P., Magiera K., Kołucki M., Galanty M., Kowalska M. Usefulness of a general anesthesia protocol and work organization in mass castration and sterilization programs for dogs and cats

\section{Summary}

The problem of homelessness of dogs and cats is addressed mainly through spay and neuter clinics. Reproduction control is particularly important for the population of dogs and cats in rural areas. The safety of general anesthesia is one of the most important elements of surgical procedures, especially when working under field conditions.

The aim of the study was to describe an anesthetic protocol used on dogs and cats during mass castration and sterilization programs which will be suitable for Polish conditions. The data were collected in the years 2009-2014 for 130 animals that underwent castration or sterilization. General anesthesia during surgical procedures was based on the use of dexmedetomidine, butorphanol, ketamine, and midazolam. The protocol was evaluated for its safety. We also compared it with anesthetic protocols used during mass castration and sterilization programs for dogs and cats in other countries.

The number of complications was very low: apnea during anesthesia was observed in one patient, that is, in $0.99 \%$ of the treated animals.

The selected protocol was assessed as safe, simple to use, and cost-effective.

Keywords: mass castration, spay, dog, cat, anesthetic protocol

There has been a growing public interest in the problem of animal homelessness. Numerous public awareness campaigns stress the importance of reducing the population of animals through castration and sterilization, which prevents their abandonment (14, 17). Therefore, organizing spay and neuter clinics, especially in areas with limited access to veterinary care, is becoming increasingly common $(7,12,15)$. Safe anesthesia and perioperative patient care during mass castration and sterilization programs is essential for patient safety.

The Polish literature provides no guidelines on the use of anesthetic protocols during spay and neuter clinics. This lack of guidelines significantly complicates the process of organizing local clinics.

In this article, we present information on the organization of our spay and neuter clinics. In particular, we focus on an anesthetic protocol designed specifically for mass castrations and sterilizations and based on clinical experience from five such events. Additionally, we compare this protocol in terms of the mode of drug administration and costs with protocols used during similar programs at St. Edward Island and Purdue University clinics $(7,12)$. This information may prove helpful to the organizers of spay and neuter clinics in selecting an anesthetic protocol suitable for Polish conditions.

\section{Material and methods}

Since 2009, five spay and neuter clinics have been organized in rural areas of Podlaskie Voivodeship in Poland by students of veterinary medicine in cooperation with the faculty and staff of the Small Animal Surgery and Anesthesiology Department of the Warsaw University of Life Sciences. The anesthesia protocol used during those mass castration and sterilization programs was designed to meet 
the needs of local clinics in Poland, and it has never been published before.

During the clinics, surgical procedures were carried out on a total of 130 animals. Ovariohysterectomy was the procedure of choice for both female dog and cat patients. Orchiectomy was used for male patients (14). Spaying was performed by an abdominal skin incision posterior to the umbilicus without incising the suspensory ligament. A total of three ties were placed for ligation: one on each ovarian pedicle and one on the uterine body. In dogs, castration was performed by prescrotal approach, and the testicles were removed by a closed method. In male cats, an open castration method was used to remove the testicles (4).

Each clinic lasted three days. Two teams of three students each worked simultaneously. Each team included an anesthesiologist, a surgeon, and an assistant. The roles were rotated among the team members so that each student could experience all aspects of surgical procedure. Each procedure was supervised by a registered veterinary surgeon. Patients were admitted according to a fixed time schedule. The owners were informed to fast their pets for 8 hours prior to the surgery (5). Upon admittance, the students performed a routine clinical examination of each patient, which included measuring the internal (rectal) temperature, recording the body weight of dogs and bitches, palpating the lymph nodes and abdomen, recording heart and respiratory rates during auscultation, as well as collecting data from an interview on the general health and reproductive status of the patient.

It is imperative to properly inform the owner about the legal aspects of the spay or neuter surgical procedure. Therefore, before the procedure, the animal owners were informed about risks associated with anesthesia and about the fact that the surgery would be performed by students supervised by a veterinary surgeon. After the animal's recovery, at discharge, the owner was advised on aftercare and possible postoperative complications.

Administration of anti-inflammatory drugs prior to surgery increases their effectiveness $(8,18)$. During the clinics, meloxicam (Metacam ${ }^{\circledR} 5 \mathrm{mg} / \mathrm{ml}$, Boehringer Ingelheim) was used at a dose of $0.2 \mathrm{mg} / \mathrm{kg}$ for dogs and $0.3 \mathrm{mg} / \mathrm{kg}$ for cats. Cats could also be given tolfenamic acid (Tolfine ${ }^{\circledR} 40 \mathrm{mg} /$ $\mathrm{ml}$, Vétoquinol Biowet) at a dose of $4 \mathrm{mg} / \mathrm{kg}$. Butorphanol (Butomidor $10 \mathrm{mg} / \mathrm{ml}$ Richter Pharma Ag), which belongs to the opioid group of drugs, as well as Ketamine $(\mathrm{K}=$ Ketamina $10 \% 100 \mathrm{mg} / \mathrm{ml}$ Biowet Puławy), were used for premedication and for the induction and maintenance of analgesia during cat procedures.

In our clinics, we chose an intramuscular injection of drugs for premedication after calculating the correct amount of anesthetics based on the patient's body weight.

After premedication, students placed intravenous catheters, prepared the operating field, and performed intubation on dog patients. Cat patients were not intubated for the procedure, because of their highly irritable larynx.

The anesthetic protocol included dexmedetomidine (Dexdomitor $^{\circledR}$ inj. Ad us vet. $0.5 \mathrm{mg} / \mathrm{ml}$, Orion Pharma Animal Health), butorphanol (Butomidor $10 \mathrm{mg} / \mathrm{ml}$ Richter Pharma Ag), ketamine (Ketamine 10\% $100 \mathrm{mg} / \mathrm{ml}$ Biowet Pulawy) and midazolam (Midanium ${ }^{\circledR} 5 \mathrm{mg} / \mathrm{ml}$ Polfa Warsaw SA). Table 1 presents the weight-specific doses of the anesthetic drugs. The table was used in this form to expedite and simplify the preparation of very small animals for surgery.
Tab. 1. Doses of anesthetic agents used for cats in spay and neuter clinics organized by students of the Veterinary Medicine Club

\begin{tabular}{|c|c|c|}
\hline Body weight & Premedication (i.m.) & Induction/Maintenance (i.v.) \\
\hline \multirow{3}{*}{$<1 \mathrm{~kg}$} & $\mathrm{D}^{1}-0.025 \mathrm{mg} / \mathrm{kg}$ & $\mathrm{D}-0.025 \mathrm{mg} / \mathrm{kg}$ \\
& $\mathrm{B}^{2}-0.5 \mathrm{mg} / \mathrm{kg}$ & $\mathrm{B}-0.5 \mathrm{mg} / \mathrm{kg}$ \\
& $\mathrm{M}^{3}-0.25 \mathrm{mg} / \mathrm{kg}$ & $\mathrm{M}-0.25 \mathrm{mg} / \mathrm{kg}$ \\
& $\mathrm{K}^{4}-5 \mathrm{mg} / \mathrm{kg}$ & $\mathrm{K}-5-10 \mathrm{mg} / \mathrm{kg}$ \\
$1-2 \mathrm{~kg}$ & $\mathrm{D}-0.0125 \mathrm{mg} / \mathrm{kg}$ & $\mathrm{D}-0.0125 \mathrm{mg} / \mathrm{kg}$ \\
& $\mathrm{B}-0.25 \mathrm{mg} / \mathrm{kg}$ & $\mathrm{B}-0.25 \mathrm{mg} / \mathrm{kg}$ \\
& $\mathrm{M}-0.125 \mathrm{mg} / \mathrm{kg}$ & $\mathrm{M}-0.125 \mathrm{mg} / \mathrm{kg}$ \\
& $\mathrm{K}-2.5 \mathrm{mg} / \mathrm{kg}$ & $\mathrm{K}-2.5-5 \mathrm{mg} / \mathrm{kg}$ \\
& $\mathrm{D}-0.0125 \mathrm{mg} / \mathrm{kg}$ & $\mathrm{D}-0.0125 \mathrm{mg} / \mathrm{kg}$ \\
& $\mathrm{B}-0.16 \mathrm{mg} / \mathrm{kg}$ & $\mathrm{B}-0.16 \mathrm{mg} / \mathrm{kg}$ \\
& $\mathrm{M}-0.08 \mathrm{mg} / \mathrm{kg}$ & $\mathrm{M}-0.08 \mathrm{mg} / \mathrm{kg}$ \\
& $\mathrm{K}-1.66-3.3 \mathrm{mg} / \mathrm{kg}$ & $\mathrm{K}-1.66-3.3 \mathrm{mg} / \mathrm{kg}$ \\
& $\mathrm{D}-0.0125 \mathrm{mg} / \mathrm{kg}$ & $\mathrm{D}-0.0125 \mathrm{mg} / \mathrm{kg}$ \\
& $\mathrm{B}-0.125 \mathrm{mg} / \mathrm{kg}$ & $\mathrm{B}-0.125 \mathrm{mg} / \mathrm{kg}$ \\
& $\mathrm{M}-0.125 \mathrm{mg} / \mathrm{kg}$ & $\mathrm{M}-0.125 \mathrm{mg} / \mathrm{kg}$ \\
& $\mathrm{K}-1.25-2.5 \mathrm{mg} / \mathrm{kg}$ & $\mathrm{K}-2.5 \mathrm{mg} / \mathrm{kg}$ \\
\hline
\end{tabular}

Explanations: ${ }^{1} \mathrm{D}=$ Dexdomitor $^{\circledR}$ inj. ad us vet. $0.5 \mathrm{mg} / \mathrm{ml}$, Orion Pharma Animal Health; ${ }^{2} \mathrm{~B}=$ Butomidor $10 \mathrm{mg} / \mathrm{ml}$ Richter Pharma Ag; ${ }^{3} \mathrm{M}=$ Midanium ${ }^{\circledR} 5 \mathrm{mg} / \mathrm{ml}$ Warszawskie Zakłady Farmaceutyczne Polfa S.A.; ${ }^{4} \mathrm{~K}=$ Ketamina $10 \% 100 \mathrm{mg} / \mathrm{ml}$ Biowet Puławy

Due to the limited availability of specialized equipment, patients under general anesthesia were monitored continuously by an anesthesiologist, who checked the patient's respiratory rate and its quality, as well as the heart rate, using a stethoscope. Additionally, the anesthesiologist assessed the patient's palpebral reflex, eye position, and jaw tone, and measured oxygen saturation with a pulseoximeter. Each animal received intravenous fluids $(0.9 \% \mathrm{NaCl}$ or Lactated Ringer's solution). Table 2 shows the anesthesia-monitoring protocol that was used to standardize the monitoring of the patients.

The fluids were warmed before administration to prevent a decrease in the patient's temperature and to reduce possible complications during surgery (1).

The postoperative period is considered to be the most critical for patient safety $(3,8)$; therefore, all patients were inspected at regular intervals for a return of motor function and consciousness. During the whole process, the patients received oxygen via an oxygen mask and were kept warm.

Patients making a slow recovery after surgery (i.e., those whose reflexes took more than 30 min to return after their surgery concluded) received atipamezole. In such cases, atipamezole was given at least 20-40 min after the last administration of ketamine in the amount of $1 / 2-1 / 4$ dose of dexmedetomidine (given in milliliters) used during anesthesia.

Data for the patients were recorded in a central database throughout each spay and neuter clinic. The records included data from the interview (name, species, sex, color, breed, body weight in kilograms, and age of the patient in years), information obtained by clinical examination, the date of the surgery, the amount of anesthetic drugs administered, anti-inflammatory medication, and antibiotics used, data from the anesthetic protocols, as well as the owner's consent to perform the procedure. The data were analyzed to evaluate the usefulness of the anesthesia scheme and work organization during spay and neuter clinics in terms of the number of animals of particular species and sex, age (reliable data regarding the age of cats were often unavailable 
and therefore were not analyzed), weight, time from administering a premedication to the beginning of the surgical procedure, time to perform ovariohisterectomy, and the level of complications.

To select an anesthesia protocol for spay and neuter clinics that would be the most suitable for Polish conditions, we compared our protocol with protocols used by St. Edward Island and Purdue University clinics $(7,12)$ in terms of the mode of medicine administration, the cost of anesthesia, maintenance of anesthesia, and the level of complications.

\section{Results and discussion}

The number of animals admitted to spay and neuter clinics (2009-2014) is shown in Fig. 1.

Surgical procedures were carried out on a total of 130 animals, $55 \%$ of which were cats (72 animals) and $45 \%$ (58 animals) were dogs. A total of 29 males were castrated, of which $65 \%$ were cats (19 animals), and 35\% were dogs (10 animals). Among the 101 spayed females, $52 \%$ were queens (53 animals), and $48 \%$ were bitches (48 animals).

The total ratio of males to females was $29: 101$.

It is known that early castration plays a key role in reducing homelessness among animals (13). Thus, the age of the patients admitted to the clinics is of interest. For epidemiological reasons, only animals over 4 months of age were qualified for surgery in our clinics. This age requirement allowed animals to establish post vaccination immunity and develop a properly functioning innate immune system (16). The youngest operated animal was 4 months old (female cat), and the oldest was 9 years old (female dog). The average ages of male and female dogs were 3 years (Standard Error $\mathrm{SE}=0.89$ ) and 2 years and 8 months (SE $=0.3$ ), respectively. Among all male and female dogs, $29 \%$ were younger than 1 year of age.

The average weight of all castrated bitches and dogs was $14.8 \mathrm{~kg}(\mathrm{SE}=3.1)$. The average weights of male and female dogs were $14.6 \mathrm{~kg}(\mathrm{SE}=4.6)$ and $15 \mathrm{~kg}$ $(\mathrm{SE}=1.6)$, respectively. Among both male and female dogs, $50 \%$ weighed more than $10 \mathrm{~kg}$. The average weight of cat patients was estimated to be $3.5 \mathrm{~kg}$ $(\mathrm{SE}=0.4)$.

The average time from administering a premedication to the beginning of
Tab. 2. Patient anesthesia chart

\begin{tabular}{|l|l|l|}
\hline Date: & Species: & Breed: \\
\hline Sex: & Age: & Weight: \\
\hline Color: & & Owner: \\
\hline
\end{tabular}

Behavior:

alert bright depressed

aggressive

Physical examination: $\quad$ T (temperature): $\quad \mathrm{P}$ (puls): $\quad$ R (respiration): lymph nodes:

\begin{tabular}{|l|l|l|l|l|l|}
\hline & Drug used & Quantity & $\begin{array}{c}\text { Mode of } \\
\text { administration }\end{array}$ & $\begin{array}{c}\text { Time of } \\
\text { administration }\end{array}$ & Effect \\
\hline Premedication & 1 & & & & \\
\hline & 2 & & & & \\
\hline & 3 & & & & \\
\hline Induction & 1 & & & & \\
\hline & 2 & & & & \\
\hline & 3 & & & & \\
\hline & 4 & & & & \\
\hline Maintenance & 1 & & & & \\
\hline & 2 & & & & \\
\hline
\end{tabular}

Time of starting the surgical procedure:

MONITORING

\begin{tabular}{|l|l|l|l|l|l|l|l|l|l|l|l|l|l|}
\hline Time & & & & & & & & & & & & & \\
\hline Heart rate & & & & & & & & & & & & & \\
\hline Respiration & & & & & & & & & & & & & \\
\hline Mucous membranes & & & & & & & & & & & & & \\
\hline $\begin{array}{l}\text { Reflexes } \\
\text { 1) palpebral } \\
\text { 2) jaw tone } \\
\text { 3) deep pain }\end{array}$ & & & & & & & & & & & & & \\
\hline Eye position & & & & & & & & & & & \\
\hline
\end{tabular}

Time of completing the surgical procedure:

Temperature (after the surgical procedure):

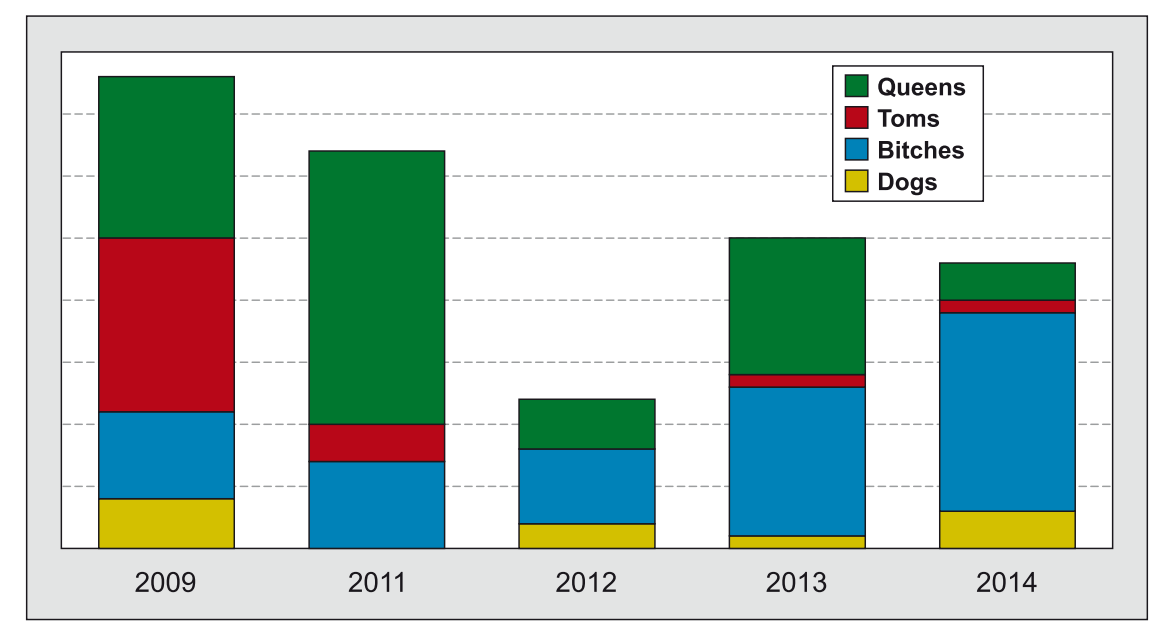

Fig. 1. The number of animals admitted to spay and neuter clinics (2009-2014) 
surgical procedure was $30 \mathrm{~min}(\mathrm{SE}=0.5)$. During our spay and neuter clinics, premedication and induction of anesthesia were sufficient for $56 \%$ of procedures, giving an average of $40 \mathrm{~min}$ to prepare the patient and carry out the procedure. In the remaining animals, anesthesia was maintained by intravenous bolus injections. The average duration of ovariohisterectomy was $45 \mathrm{~min}$ $(\mathrm{SE}=2.1)$.

The number of complications during anesthesia was low: apnea was observed in one patient, that is, in $0.99 \%$ of all animals.

Spay and neuter clinics held on Prince Edward Island (7) used a combination of ketamine $(22 \mathrm{mg} / \mathrm{kg})$ and acepromazine $(0.01 \mathrm{mg} / \mathrm{kg})$ or ketamine and butorphanol $(0.05 \mathrm{mg} / \mathrm{kg})$ for premedication and isoflurane administered by mask for maintaining anesthesia. The drug doses administered were based on the estimated weight. The protocol of anesthesia proposed by veterinarians from Purdue University, USA, consisted of a combination of tiletamine-zolazepam (telazol powder) dissolved in $2.5 \mathrm{ml}$ of dexmedetomidine and in $2.5 \mathrm{ml}$ of butorphanol (10). During a program organized by Purdue University, drugs were administered by intramuscular injection, although intravenous administration was possible with half a dose. The drug doses were based on the estimated weight. A multimodal anesthetic at a dose of $0.4 \mathrm{ml}$ per kilogram of body weight in both dogs and cats maintained its action for up to $50 \mathrm{~min}$ (10). A comparison of the three different protocols used during spay and neuter clinics is shown in Table 3.

A veterinarian needs to anticipate a number of specific issues which may occur when procedures are carried out under field conditions. These issues include a large number of patients of different ages and weights, very limited diagnostic capabilities prior to surgery, unknown medical history and health status of the patients, impossibility of hospitalizing the patients or monitoring them during recovery, limited availability of specialized equipment, limited finances, and limited time available for procedures. Additionally, ovariohysterectomy procedures are painful and therefore require adequate analgesia. It should be noted that, due to time and operating room constraints, all animals were operated on as they appeared upon arrival. This means that the routine procedure of ovariohysterectomy (unlike in everyday practice) was performed on females that were pregnant, in estrus, or had pyometra, which increased the risk during surgery.

An ideal anesthetic protocol must ensure both patient safety and a sufficient level of anesthesia for the veterinary surgeon to securely proceed through the surgery.
Therefore, the protocol used should: 1 . provide a wide margin of safety; 2 . ensure fast induction, an appropriate level of muscle relaxation, and loss of consciousness; 3 . guarantee perioperative analgesia; 4 . be effective and predictable in action on animals of different ages and health status; 5 . be easily reversible and provide a rapid return of all vital functions after surgery; 6 . use cost-effective and easily available drugs (10). In our opinion, the above criteria are met under field conditions by the use of intravenous anesthesia, which provides greater control over the level of anesthesia than the use of intramuscular anesthetics.

It is recommended (2) that the anesthetic protocol should consist of drugs belonging to the $\alpha 2$-agonists, opioids, and dissociative anesthetics (such as ketamine), which should all be administered in a single injection. This combination has all the advantages of multimodal anesthesia, which limits side effects, and makes it possible to use smaller doses of each drug (7). These advantages, offered by our anesthesia protocol, are particularly important for spay and neuter clinics.

In our opinion, determining the amount of drugs used on the basis of the estimated body weight creates unnecessary risks, which should be avoided if possible. Nevertheless, the use of estimated body weight may be necessary when dealing with large numbers of patients, such as in spay and neuter clinics organized by universities in the United States $(7,12)$.

Aside from the dosage and way of administration, the maintenance of anesthesia is another important distinction between different anesthetic protocols. A single intramuscular injection significantly expedites the work of the veterinary team. On the other hand, an inhalation anesthetic offers a large safety margin and the ability to easily control the depth of anesthesia, as well as provides a quick recovery. These characteristics make it the most desirable form of anesthesia for such programs (11).

The financial aspect and the availability of drugs are important when selecting an anesthetic protocol. Tiletamine-zolazepam (telazol powder) anesthetic applied by the veterinary team of Purdue University is not available in Poland. The need to import drugs creates an additional hurdle in organizing such programs and may further increase their cost. Therefore, it seems reasonable to use resources available locally. Moreover, the use of drugs that are familiar to the anesthesiologist and whose action is well known and predictable increases the safety of anesthesia.

The aforementioned protocols also generated much higher costs compared with ours. The estimated cost of our anesthetic protocol was one-eight the cost of that

Tab. 3. Comparison of anesthesia protocols

\begin{tabular}{|c|c|c|c|c|}
\hline \multirow{2}{*}{ Organizers of spay and neuter clinics } & \multicolumn{3}{|c|}{ Mode of administration } & \multirow{2}{*}{$\begin{array}{l}\text { Mortality } \\
\text { rate }\end{array}$} \\
\hline & & Premedication & Maintenance of anesthesia & \\
\hline St. Edward Island, Canada & Intramuscular injection & According to estimated body weight & Inhalation anesthesia & 0 \\
\hline Purdue University, USA & Intramuscular injection & According to estimated body weight & Single intramuscular injection & 0 \\
\hline $\begin{array}{l}\text { SGGW, Poland Small Animal Surgery } \\
\text { and Anesthesiology Department }\end{array}$ & Intramuscular injection & $\begin{array}{l}\text { According to estimated body weight in cats } \\
\text { According to exact body weight in dogs }\end{array}$ & Intravenous anesthesia & 0 \\
\hline
\end{tabular}


used by the St. Edward Island clinic and one-ninth the cost generated by that of Purdue University.

The safety of the anesthetic protocol depends partially on using drugs with antagonistic effects that could reverse anesthesia at any time. Theoretically, apart from ketamine, it is possible to reverse the effect of anesthetics listed in our protocol by administering drugs containing naloxone or flumazenil. These drugs, however, are not available in Poland. Therefore, atipamezole which is readily available, has been used. It is an alpha2-antagonist, and it has the ability to inhibit the effects of dexmedetomidine (10).

Unlike similar clinics organized abroad, our clinics did not conduct a rigorous selection of patients, did not perform routine tests for FIV or FeLV in cats, and did not take into account the estrous cycle phase in bitches $(7,12)$. It is very likely that assessments based on clinical examination could be inadequate in detecting animals with subclinical diseases or those suffering from parasitosis, which could further increase the risk of anesthesia. However, in the opinion of the authors of this article and the authors of Anesthesia and Analgesia Guidelines for High Quality, High Volume Spay/Neuter Initiatives, the benefits of the surgery take precedence over the risk (12).

Currently, it is ideal to determine the safety of the protocol on the basis of long-term consequences associated with anesthetic drug usage rather than the mortality rate. However, during mass spay and neuter programs, long-term patient monitoring is impossible. For this reason, the mortality rate is still taken into account in the assessment of protocol safety. No deaths were noted in spays and neuters performed according to the above protocols. This may have been influenced by the fact that, prior to each procedure, the patients on St. Edward Island were tested for infectious diseases, such as FeLV and FIV, which could have affected mortality.

One study by the Royal Veterinary College determined the risk of death associated with anesthesia in healthy patients as $0.1-0.2 \%$ and in sick patients as $0.5-2 \%$ (3). In contrast, studies in New York showed that anesthetic mortality rates among cats during spay and neuter clinics were $0.08-0.16 \%(6)$. This fact shows that doctors of veterinary medicine can greatly influence the safety of their patients. One should not only choose the right anesthetic protocol, but also closely monitor the anesthetized patient and correctly respond to any problems that may arise during surgery (2). According to the United States Association of Shelter Veterinarians' Standards, the most important elements of patient safety during surgery are fluid therapy, preventing body temperature decrease (animals with reduced body heat take longer to recover due to the slower metabolism of drugs (9)), and the proper monitoring of the patient during the induction phase of anesthesia and under sedation (12).

The outcomes of the clinic show that such programs carried out by the university are beneficial for students in gaining a theoretical and practical knowledge of medicine and ultimately contribute to reducing the number of homeless animals. Moreover, they raise public awareness of the importance of spaying and neutering. However, given the large number of animal patients, spay and neuter clinics require a careful organization of time and a faultless anesthetic protocol.

When analyzing the data collected, the participants concluded that in the future the risk of adverse effects of anesthetic agents in spay and neuter clinics should be minimized by shortening the duration of the procedure.

Mass spay and neuter clinics do not exist in Poland, so there are no Polish data on these procedures that could be compared with those in the United States $(6,7,12)$. Our data shows that an anesthetic protocol based on dexmedetomidine, midazolam, butorphanol, and ketamine is ideal in terms of safety (multimodal anesthesia, commonly used anesthetic agents with reversible effect administered according to exact body weight), adequate anesthesia level, low price, and availability of drugs. It meets the needs of spay and neuter clinics, follows shelter medicine recommendations, and is therefore suitable for outside clinics in Poland. It offers a new, safe and easy method of performing spay and neuter procedures under field conditions.

\section{References}

1. Armstrong S. R., Roberts B. K., Aronsohn M.: Perioperative hypothermia. J. Vet. Emerg. Crit. Care 2005, 15, 32-37.

2. Bednarski R., Grimma K., Lukasik V. M., Penn W. S., Sargent B., Spelts K.: AAHA Anesthesia Guidelines for Dogs and Cats. J. Am. Anim. Hosp. Assoc. 2011, 43, 377-385.

3. Brodbelt D.: Perioperative mortality in small animal anaesthesia. Vet. J. 2009, $182,152-161$.

4. Fossum T. W., Dewey C. W., Horn C. V., Johnson A. L., MacPhail C. M., Radlinsky M. G., Schulz K. S., Willard M. D.: Surgery of the Reproductive and Genital Systems. Small Anim. Surg. Elsevier St. Louis, MO 2012.

5. Galatos A. D., Raptopoulos R.: Gastro-oesophageal reflux during anaesthesia in the dog: the effect of preoperative fasting and premedication. Vet. Rec. 1995, 19, 479-483.

6. Gerdin J. A., Slater M. R., Makolinski K. V., Looney A. L., Appel L. D., Martin N. M., McDonough S. P.: Post-mortem findings in 54 cases of anesthetic associated death in cats from two spay-neuter programs in New York State. J. Feline Med. Surgery 2011, 13, 959-966.

7. Gibson K. L., Keizer K., Golding C.: A trap, neuter, and release program for feral cats on Prince Edward Island. Can. Vet. J. 2002, 43, 695-698.

8. Ilkiw J. E.: Balanced Anesthetic Techniques in Dogs and Cats. Clin. Tech. Small Anim. Pract. 1999, 14, 27-37.

9. Insler S. R., Sessler D. I.: Perioperative thermoregulation and temperature monitoring. Anesthesiol. Clin. 2006, 4, 823-837.

10. Ko J. C., Berman A. G.: Anesthesia in Shelter Medicine. Companion Anim Med. 2010, 25, 92-97.

11. Lamont L. A.: Multimodal Pain Management in Veterinary Medicine: The Physiologic Basis of Pharmacologic Therapies. Vet. Clin. North Am. Small Anim. Pract. 2008, 38 1173-1186.

12. Looney A. L., Bohling M. W., Bushby P. A., Howe L. M., Griffin B., Levy L. K. The Association of Shelter Veterinarians veterinary medical care guidelines for spay-neuter programs. J. Am. Vet. Med. Assoc. 2008, 233, 74-86.

13. New J. C. Jr, Kelch W. J., Hutchison J. M., Salman M. D., King M., Scarlett J. M., Kass P. H.: Birth and death rate estimates of cats and dogs in U.S. households and related factors. J. Appl. Anim. Welf. Sci. 2004, 7, 229-241.

14. Olson P. N., Johnson S. D.: New developments in small animal population control. J. Am. Vet. Med. Assoc. 1993, 202, 904-909.

15. Schultz R. D.: Current and future canine and feline vaccination programs Association of Shelter Veterinarians' Spay-Neuter Task Force Looney. Veterinary Medicine 1998, 93, 233-254.

16. Schultz R. D., Thiel B., Mukhtar E., Sharp P., Larson L. J.: Age and Long-term Protective Immunity in Dogs and Cats. J. Comp. Path. 2010, 142, 102-108.

17. Sparkes A. H., Bessant C., Cope K., Ellis S. L. H., Finka L., Halls V., Hiestand K., Horsford K.: Guidelines on Population Management and Welfare of Unowned Domestic Cats (Felis catus). J. Feline Med. Surg. 2013, 15, 811-817.

18. Woolf, Clifford J., Chong, Mun-Seng: Preemptive Analgesia-Treating Postoperative Pain by Preventing the Establishment of Central Sensitization. Anesthesia Analgesia 1993, 77, 362-379.

Corresponding author: Beata Degórska, PhD, Nowoursynowska 159c, 02-776 Warsaw, Poland; e-mail:beata_degorska@sggw.pl 